\title{
Rainfall patterns of Algerian steppes and the impacts on natural vegetation in the $20^{\text {th }}$ century
}

\author{
Fahima BELALA ${ }^{1 *}$, Azziz HIRCHE ${ }^{1,2}$, Serge D MULLER ${ }^{3}$, Mahmoud TOURKI $^{4}$, Mostefa \\ SALAMANI ${ }^{1}$, Mohamed GRANDI ${ }^{1,5}$, Tahar AIT HAMOUDA ${ }^{6}$, Madjid BOUGHANI ${ }^{1}$ \\ ${ }^{1}$ Laboratory of Plant Ecology, Faculty of Biological Sciences, University of Sciences and Technology Houari Boumediene, \\ Wilaya 16000, Algeria; \\ ${ }^{2}$ Scientific and Technical Research Center on Arid Regions, Biskra 7000, Algeria; \\ ${ }^{3}$ Institute of Evolutionary Sciences, University of Montpellier-CNRS, Montpellier 34095, France; \\ ${ }^{4}$ Department of Hydraulics, University of Badji Mokhtar, Annaba 23000, Algeria; \\ ${ }^{5}$ Faculty of Nature Sciences, University of Saad Dahlab, Blida 9000, Algeria; \\ ${ }^{6}$ Faculty of Sciences, University of Yahia Farès, Wilaya 26000, Algeria
}

\begin{abstract}
Since 1960, the steppe regions of North Africa have been subject to an increasing desertification, including the degradation of traditional pastures. The initially dominant species (Artemisia berba-alba, Lygeum spartum and Stipa tenacissima) declined and were progressively replaced by other species (Atractylis serratuloides and Salsola vermiculata) that are more tolerant to the new conditions. It is not clear whether these changes are due to anthropogenic reasons or climatic determinism. We have carried out a statistical analysis of the climate to detect putative rainfall changes during the $20^{\text {th }}$ century in the Algerian steppes based on data from 9 meteorological stations, including 2 Saharan stations (El Oued and Touggourt), 3 pre-Saharan stations (Biskra, Laghouat and Ain Sefra) and 4 steppe stations (Djelfa, Saida, Méchéria and El-Bayadh) located in the arid high plains, which represent the bioclimate diversities of the region. Previous studies suggested that significant rainfall changes for the $20^{\text {th }}$ century only had records in the south of the Oran region. Most of the studies, however, looked at restricted territories over limited periods, and did not integrate the rainiest period 2004-2014. Our work is designed to integrate all the longest time series of meteorological data available for the steppe regions of Algeria. Our results confirm the spatial rainfall distribution (significant rainfall changes only recorded in the southwestern region) evidenced by previous studies, and reveal a decreasing rainfall gradient from northeastern to southwestern Algeria. Moreover, the results reveal a trend of significant decrease of rainfall in the southern Oran region, marked by two drought periods in 1980 1985 and 1999-2003. However, with the exception of the southwestern region, rainfall overall has not declined since the beginning of the $20^{\text {th }}$ century. While less marked in other regions, the drought appear to have affected all territories of the Algerian steppe. Consequently, our study implies that the climate was not a leading influence in the on-going degradation of the vegetation cover of steppe landscapes. Such a vegetation evolution thus appears to be have been determined more by human activities than by climate forcing.
\end{abstract}

Keywords: climate; arid and semi-arid regions; drought; rangeland degradation; human impact; North Africa

Citation: Fahima BELALA, Azziz HIRCHE, Serge D MULlER, Mahmoud TOURKI, Mostefa SALAMANI, Mohamed GRANDI, Tahar AIT HAMOUDA, Madjid BOUGHANI. 2018. Rainfall patterns of Algerian steppes and the impacts on natural vegetation in the $20^{\text {th }}$ century. Journal of Arid Land, 10(4): 561-573. https://doi.org/10.1007/s40333-018-0095-x

\footnotetext{
*Corresponding author: Fahima BELALA (E-mail: fahima.belala@gmail.com)

Received 2017-10-26; revised 2018-01-15; accepted 2018-06-06

(C) Xinjiang Institute of Ecology and Geography, Chinese Academy of Sciences, Science Press and Springer-Verlag GmbH Germany, part of Springer Nature 2018
} 


\section{Introduction}

It is generally accepted that the causes of desertification are related to anthropogenic activities and environmental factors, mainly climate forcing. The relative importance of these factors has long been debated. An initial and enduring school of thought, enhanced by Le Houérou, focused on human activities. His paradigm can be summarized by two expressions: 'man-made deserts' and 'man is not the son but the father of deserts' (Le Houérou, 1989; Reynolds et al., 2007). Another school of thought, based largely on the experience of drought in Sahel, considers that climate is the most decisive factor impacting rangelands both in the short (Nicholson, 2000, 2005; Herrmann et al., 2005a, b; Herrmann and Hutchinson, 2005; Gonzalez et al., 2012) and long term (Lhote, 1975; Muzzolini, 1993).

Desertification is a great concern in North Africa, especially in Maghreb. Numerous researchers have discussed the roles of overgrazing and drought on desertification in the Saharan margins (Djebaili, 1978; Le Houérou, 1989, 1996; Aidoud et al., 1998; Nedjraoui, 2003; Benbrahim et al., 2004; Hanafi and Jauffret, 2008; Hirche, 2010; Slimani et al., 2010). The Algerian steppe zone is the sheep homeland and plays a major economic role (Hirche et al., 2011; Hourizi et al., 2017). It is crucial to explore the causes and process of desertification. According to MARA (1974) and BNEDER (2006), the area of Algerian steppe increased from $2.0 \times 10^{7}$ to $27.0 \times 10^{7} \mathrm{hm}^{2}$ in about 25 years. Studies (Djebaili, 1978; Le Houérou, 1989, 1996; Aidoud et al., 1998; Nedjraoui, 2003; Hirche, 2010; Slimani et al., 2010) suggested that the desertification was mainly caused by human activities, such as agriculture and grazing.

However, previous studies produced no evidence of obvious climate change in Algeria between 1900 and 1970 (Djellouli, 1981, Daget and Djellouli, 1991), which was also supported by Le Houérou (1996). Later studies (Meddi and Hubert, 2003; Meddi and Meddi, 2004, 2007, 2009a, b; Slimani et al., 2010) revealed that the drought periods started since the 1980s, which had dramatic consequences on the steppe rangelands, particularly in the southern Oran region of northwest Algeria). Based on the data from 8 meteorological stations from 1907 to 2003, Hirche et al. (2007) dealed with the evolution of annual precipitation at a larger spatial scale, and extended the interest to the entire arid steppe region of Algeria. The results show that only the southwestern Oran region displays a significant climate trend towards drought. If the aridification of the southern Oran region persists or increases, the predominance of the anthropozoic influence could be challenged. Climate could then be given the leading role as in the Sahel (Gagnol and Soubeyran, 2012). But the last decade was relatively wet in Algeria, which raises some questions: What is the present-day climate situation? Did these wet years change the decreasing trend observed by Hirche et al. (2007)? Has the rainfall trend changed since then?

This study aims at updating the work of Hirche et al. (2007) by (1) extending the study period to 1900-2015; (2) improving the statistical treatment; (3) reconsidering the year separating the two compared periods; and (4) identifying putative impacts of climate change on livestock, agriculture, and demography.

\section{Materials and methods}

\subsection{Study area}

The study area $\left(32^{\circ} 18^{\prime}-36^{\circ} 06^{\prime} \mathrm{N}, 01^{\circ} 41^{\prime} \mathrm{W}-08^{\circ} 30^{\prime} \mathrm{E}\right.$; Fig. 1) covers the semi-arid, pre-Saharan, and Saharan bioclimates (Quézel et al., 1962), with mean annual precipitations of 200-400, 100-200, and $<100 \mathrm{~mm}$, respectively. The main climatic parameters influencing aridity in Algeria are rainfall intensity and frequency, which are conditioned by two geographical gradients. One is a north-south gradient, with rainfall decreasing southwards. Indeed, the Tell Atlas Mountain and the Saharan Atlas retain a large amount of water brought by clouds and leave the corridor area corresponding to the steppe relatively dry. Another one is the air masses dried by their displacement on the Spanish mainland, reach the North West Africa and spread to its eastern part., the air masses regain moisture as they move and result in greater rainfall in the eastern regions (Djellouli, 1981). 


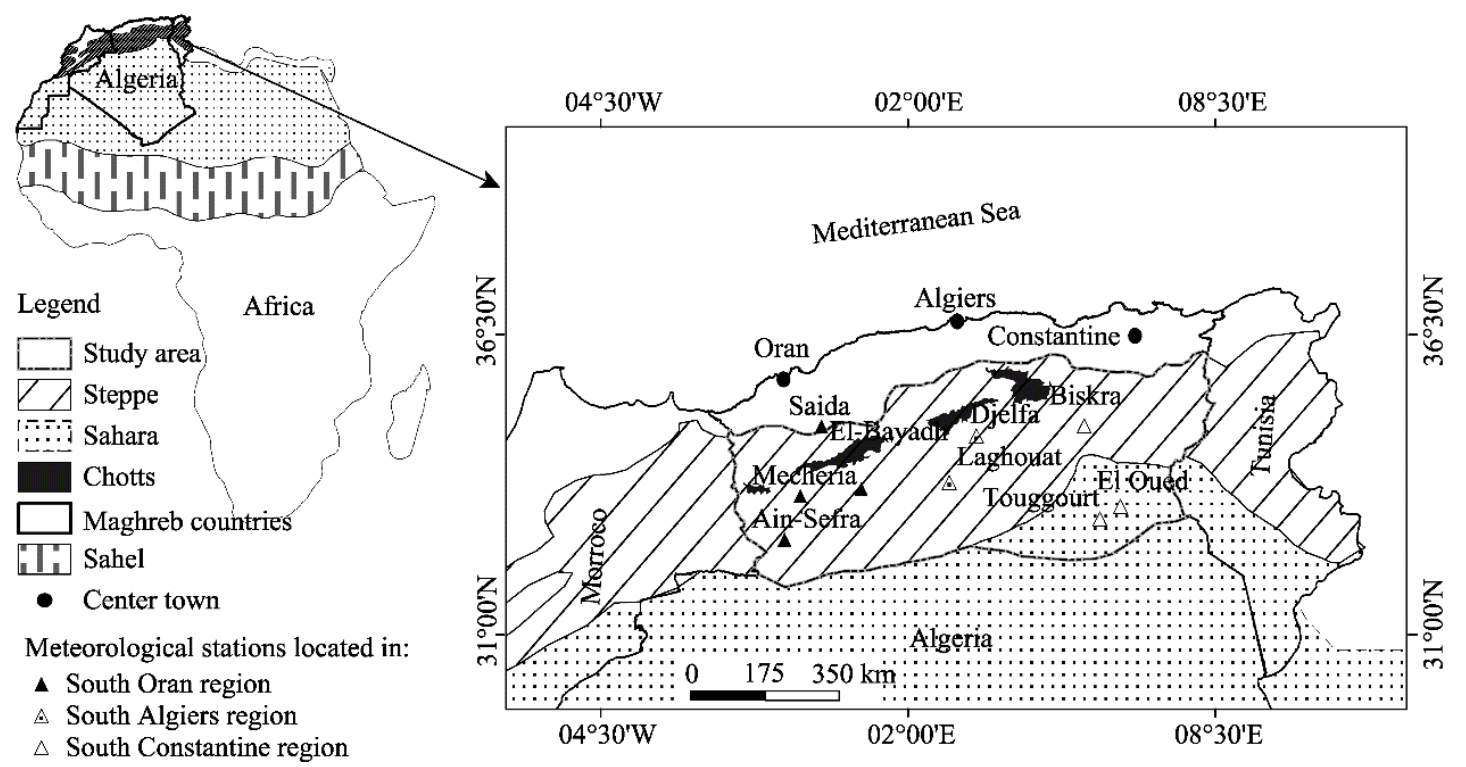

Fig. 1 Localization of the study area

\subsection{Data and methods}

\subsubsection{Climate data}

Climate data back to 1900 from the 9 meteorological stations represent bioclimates in the study area. These stations are located in the arid and semi-arid regions of Algeria, including 2 Saharan stations (El Oued and Touggourt), 3 pre-Saharan stations (Biskra, Ain Sefra and Laghouat), and 4 stations on the high plains (Djelfa, Saida, Mecheria and El Bayadh) (Fig. 1). The monthly rainfall data were observed during the period 1900-2014 and the data sources are presented in Table 1.

Table 1 Climate data source

\begin{tabular}{ll}
\hline Observation period & \multicolumn{1}{c}{ Data source } \\
\hline $1900-1938$ & $\begin{array}{l}\text { Food and Agriculture Organization of the United Nations (http://www.fao.org; Seltzer et al., 1946) } \\
\text { Centre of Spanish Hydrographic Surveys }\end{array}$ \\
& $\begin{array}{l}\text { Algerian Institute of Meteorology and Physics of the Globe } \\
\text { National Oceanic and Atmospheric Administration (http://www.noaa.gov) }\end{array}$ \\
& National Office of Meteorology \\
\hline
\end{tabular}

Climate data series are 100 years for El-Bayadh, Biskra, Djelfa and Saida (1914-2014), 101 years for El Oued and Touggourt (1913-2014), 106 years for Mecheria (1907-2013) and 110 years for Laghouat (1900-2010). Some periods are lacking monthly or annual data series, especially during and just after the war of independence (1954-1962). Years comprising at least 4 missing monthly records and years comprising missing records in the rainy seasons were withdrawn. For other years ( 1 to 3 missing monthly records in the dry season), missing data were replaced by the average of the concerned month during the related periods of 1900-1973 (period 1) or 1973-2015 (period 2) (Table 2).

2.2.2 Agricultural and demographic data

Data before independence (1962) were gathered from the Official Bulletin of the General Government of Algeria (1861-1926) and the Official Journal of Algeria (1927-1962). Since 1962, livestock and agricultural data were collected from the Agricultural Database of the Algerian Ministry of Agriculture (1962-2016), and the demographic data were taken from the National Statistics Office (ONS). The population data were from 1845 to 2015 . Livestock and barley production cover the period 1901-2014. 
Table 2 Bioclimates, geographical coordinates and periods of climate series used for each meteorological station

\begin{tabular}{llllccc}
\hline Station & Bioclimate & Latitude & Longitude & Altitude $(\mathrm{m})$ & Period 1 & Period 2 \\
\hline El-Bayadh & Semi-arid & $33^{\circ} 40^{\prime} \mathrm{N}$ & $01^{\circ} 00^{\prime} \mathrm{E}$ & 1341 & $1914-1973$ & $1974-2014$ \\
Djelfa & Semi-arid & $34^{\circ} 20^{\prime} \mathrm{N}$ & $03^{\circ} 23^{\prime} \mathrm{E}$ & 1180 & $1914-1973$ & $1974-2014$ \\
Mecheria & Semi-arid & $34^{\circ} 31^{\prime} \mathrm{N}$ & $00^{\circ} 17^{\prime} \mathrm{W}$ & 1149 & $1907-1973$ & $1974-2013$ \\
Saida & Semi-arid & $34^{\circ} 52^{\prime} \mathrm{N}$ & $00^{\circ} 09^{\prime} \mathrm{E}$ & 750 & $1914-1973$ & $1974-2014$ \\
Ain sefra & Pre-Saharan & $32^{\circ} 46^{\prime} \mathrm{N}$ & $00^{\circ} 36^{\prime} \mathrm{W}$ & 1058 & $1901-1973$ & $1974-2014$ \\
Biskra & Pre-Saharan & $34^{\circ} 48^{\prime} \mathrm{N}$ & $05^{\circ} 44^{\prime} \mathrm{E}$ & 82 & $1914-1973$ & $1974-2013$ \\
Laghouat & Pre-Saharan & $33^{\circ} 77^{\prime} \mathrm{N}$ & $02^{\circ} 93^{\prime} \mathrm{E}$ & 765 & $1900-1973$ & $1974-2010$ \\
El Oued & Saharan & $33^{\circ} 05^{\prime} \mathrm{N}$ & $06^{\circ} 12^{\prime} \mathrm{E}$ & 63 & $1913-1973$ & $1974-2014$ \\
Touggourt & Saharan & $33^{\circ} 12^{\prime} \mathrm{N}$ & $06^{\circ} 13^{\prime} \mathrm{E}$ & 85 & $1913-1973$ & $1974-2014$ \\
\hline
\end{tabular}

\subsubsection{Vegetation data}

Algeria is involved in the Sahara and Sahel Observatory/Long-term Ecological Survey Observatories Network (OSS/ROSELT), which aims to follow the evolution of vegetation in semiarid areas. OSS/ROSELT notes that the Algerian steppe landscape was mainly dominated by alfa (Stipa tenacissima), esparto (Lygeum spartum) and sagebrush (Artemisia herbaalba) but the new vegetation units representing the regressive dynamics of the steppe region are dominated by some specific species, such as Atractylis serratuloides, Peganum harmala and Salsola vermiculata. The vegetation cover was generally greater than $25 \%$ in 1975 , and the average perennial phytomass for herbaceous formations was around 1000, 650, 450, 280 and $307 \mathrm{~kg}$ dry mass $/ \mathrm{hm}^{2}$ in 1975, 1998, 2004, 2010 and 2015 (ROSELT, 2005; Hourizi et al., 2017), respectively.

\subsection{Graphical analysis}

The rainfall evolution can be appreciated initially by a graphic visualization of inter-annual rainfall. The graphs would be based on raw data and smoothed data generated by moving averages (moving average over a period of five years). Smoothed averages reduce the amplitude of inter-annual fluctuations and produce sharper curves thus more clearly revealing the trends.

\subsection{Statistical analysis}

The putative existence of rainfall trends has been analyzed using nonparametric tests that are, in comparison with parametric tests, more robust and less sensitive to non-normality but even less powerful. However, in our case study, this gap was reduced by lengthening the series. Two statistical analyses, the Mann-Whitney and Mann-Kendall tests, were used. First, they aimed to improve the robustness of the climate trend study by adding a second statistical, nonparametric method (Mann-Whitney U-test) in addition to the Mann-Kendall test already used by Hirche et al. (2007). Second, we excluded a meteorological station, El-Kheiter, from the Hirche et al. (2007) database because of the unreliability of the records and added two supplementary pre-Saharan stations, Ain Sefra and Laghouat. Third, unlike Hirche et al. (2007) who divided their time series into two equally long periods by using 1960 as their limit, we used 1972-1973, previously evidenced as a break of stationarity of climate series. Fourth, we studied the putative impact of climate change on anthropogenic activities by comparing our climate data to socio-economic data. All statistical analyses were made using XLSTAT version 2014.4.

\subsubsection{Mann-Whitney U test}

The Mann-Whitney $U$ test is an alternative form of the Wilcoxon Rank-Sum test for independent samples (Wilcoxon, 1945). It considers two samples $U_{1}$ and $U_{2}$ defined as follows:

$$
\begin{aligned}
& U_{1}=n_{1} n_{2}+\frac{n_{1}\left(n_{1}+1\right)}{2}-R_{1}, \\
& U_{2}=n_{1} n_{2}+\frac{n_{2}\left(n_{2}+1\right)}{2}-R_{2},
\end{aligned}
$$

where $n_{1}$ and $n_{2}$ are the sizes of the first and second samples respectively; $R_{1}$ and $R_{2}$ are the adjusted 
rank sum for $U_{1}$ and $U_{2}$, respectively (with $U=\operatorname{Min}\left(U_{1}, U_{2}\right)$ ).

To test the rainfall trend hypothesis, the earlier Wilcoxon version of the Mann-Whitney U test considers that the test is significant if the global observed value $(U)$ is less than the critical threshold value $\left(U_{\text {crit }}\right)$, at the designated fixed level $(\alpha)$. Hence, the null hypothesis is rejected. However, the values of $U_{\text {crit }}$ for $\alpha=0.05$ (two-tailed) are given in the Mann-Whitney Tables.

2.4.2 The Mann-Kendall test

The Mann-Kendall test calculates the average of the calculated series $E(M)$ (Sprent, 1992). It includes calculating each term in the series, the number of previous terms that are inferior to it. $M$ is the sum of the numbers thus calculated (Sneyers et al., 1998) and it corresponds to the number of values lower than $E(M)$. In the case where there is no tendency, the average is equal to:

$$
E(M)=n \frac{n(n-1)}{4},
$$

where $n$ is the number of data.

And the associated variance is:

$$
\sigma^{2}=\frac{2 n^{3}+3 n^{2}-5 n}{72},
$$

where $n$ is the annual rainfall record ( $\mathrm{mm})$; and $\sigma$ is the standard deviation ( $\mathrm{mm}$ ).

The Mann-Kendall test is based on the statistical comparison between the average of series $(X)$ and the average of the calculated series $E(M)$ :

$$
N=\frac{|X-E(M)|}{\sigma}=\frac{S}{\sigma},
$$

where $X$ is the average of the recorded series; and $N$ follows a standard normal law. We then consider that the null hypothesis $(\mathrm{H} 0)$ corresponds to the absence of trend and that $\mathrm{H} 1$ corresponds to the presence of the trend in the series.

The difference between $X$ and $E(M)$ will be significant at the $95 \%$ confidence level if $N$ is greater than 1.96 , and highly significant at the threshold of $1 \%$ if $N>2.57$. Another way to conclude is to use the "P-value". Since the calculated $P$-value is below the level of $\alpha=0.05$, one must reject the null hypothesis $\mathrm{H} 0$, and retain the alternative hypothesis $\mathrm{H} 1$. We can compare the computed $N$, the ponderate difference between $X$ and $E(M)$ to 1.96 (the first approach) or using the $P$-value (the second approach). It is this second approach that will be retained in this work.

The continuity correction was applied. Ex-aequo was detected and the appropriate corrections have been made. The autocorrelation was taken into account using Hamed and Rao (1999).

\section{Results}

\subsection{Climate data statistics}

Climate records from the 9 meteorological stations have been compiled in a matrix containing the calculated averages (Table 3). The total averages confirm the attribution of the stations to the different bioclimatic zones. The coefficient of variation is calculated by dividing the standard deviation by the average, which reveals a strong inter-annual variability. The highest coefficient of variations $(52 \%-55 \%)$ were obtained for the Saharan stations El Oued and Touggourt, and for a pre-Saharan station, Biskra. The stations located in the high plains display lower coefficient of variations of $26 \%-41 \%$.

\subsection{Century-scale rainfall trends}

For each geographical location, we visualized the results using line graphs to display the moving averages and to highlight the trend in each station. Figure 2 shows that three rainfall series of the eastern-most stations (Biskra, Touggourt and El Oued) have displayed similar trends since the beginning of the century. The figure shows alternating dry and wet periods in varied duration. The wet periods lasted not more 5 years and dry periods are not longer than 8 years. Hirche et al. (2007) found similar results. This visual analysis shows no obvious trend for these stations even though 
they are located in different geographical locations. They nevertheless evidenced dry periods in 1922-1925 (only shown in Biskra), 1943-1946, 1981-1985 and 2000-2003.

Table 3 Rainfall characteristics of the meteorological stations

\begin{tabular}{|c|c|c|c|c|c|}
\hline \multirow{2}{*}{ Station } & \multicolumn{3}{|c|}{ Annual average rainfall $(\mathrm{mm} / \mathrm{a})$} & \multirow{2}{*}{ CV $(\%)$} & \multirow{2}{*}{ WRD (\%) } \\
\hline & Total & Period 1 (M1) & Period 2 (M2) & & \\
\hline El-Bayadh & 290.10 & 310.68 & 268.53 & 31.03 & -15.69 \\
\hline Djelfa & 321.18 & 326.58 & 311.92 & 27.36 & -4.70 \\
\hline Mecheria & 264.22 & 290.40 & 229.09 & 41.77 & -26.76 \\
\hline Saida & 395.45 & 428.17 & 350.03 & 26.18 & -22.32 \\
\hline Ain sefra & 181.29 & 180.33 & 182.70 & 45.41 & 1.29 \\
\hline Biskra & 139.97 & 146.91 & 129.00 & 55.41 & 13.88 \\
\hline Laghouat & 171.60 & 174.06 & 166.86 & 38.70 & -4.31 \\
\hline El Oued & 76.75 & 80.60 & 72.08 & 51.78 & -11.82 \\
\hline Touggourt & 68.94 & 72.30 & 64.13 & 52.41 & -12.74 \\
\hline
\end{tabular}

Note: CV, coefficient of variation; WRD, weighted relative difference between M1 and M2 ((M1-M2)×100/M1).

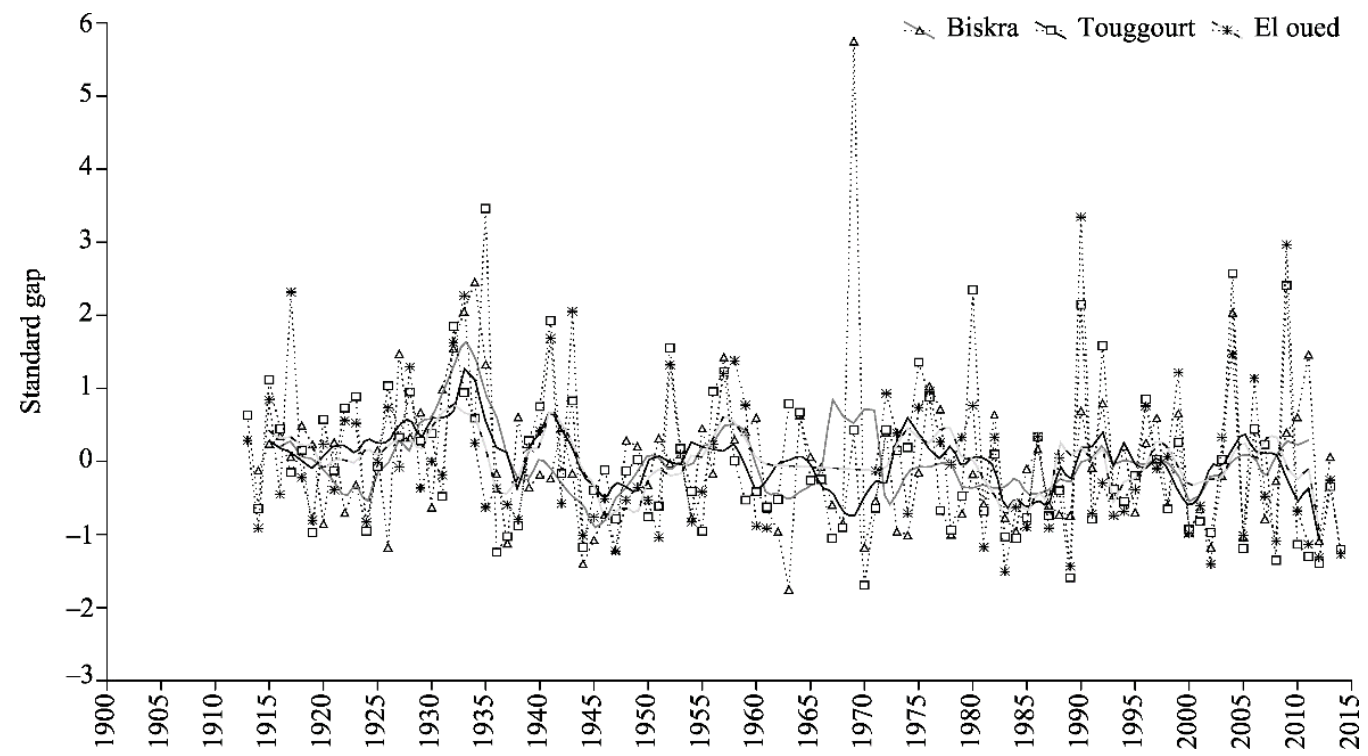

Fig. 2 Evolution of rainfall in the eastern stations of Biskra (pre-Saharan bioclimate), Touggourt and El Oued (Saharan bioclimate)

In the southern Algiers region (Fig. 3), average annual rainfall of Djelfa (semi-arid) and Laghouat (pre-Saharan) show similar trends since 1940 but having different trends before. For the whole period, they both show very important inter-annual variations compared to the eastern stations (Fig. 2) which had no clear trend and recorded alternating wet and dry periods and evidenced several particularly long dry periods in 1940-1950, 1980-1985 and 1999-2004. The evolution in the westernmost pre-Saharan station of Ain Sefra is similar to Laghouat and to a lesser extent to Djelfa (Fig. 3), albeit characterized by longer dry periods (1935-1950, 1976-1988 and 1995-2005).

The stations in the southern Oran region (Mecheria, El-Bayadh and Saida) highlight a difference between the two periods separated by the year 1973 (Fig. 4). The first part of the century is clearly humid, with a moving average that is almost always above the average, standard gap with the exception of the dry period 1940-1950. The second half of the century appears much drier, especially from 1975 to 1990 and from 1999 to 2005. 


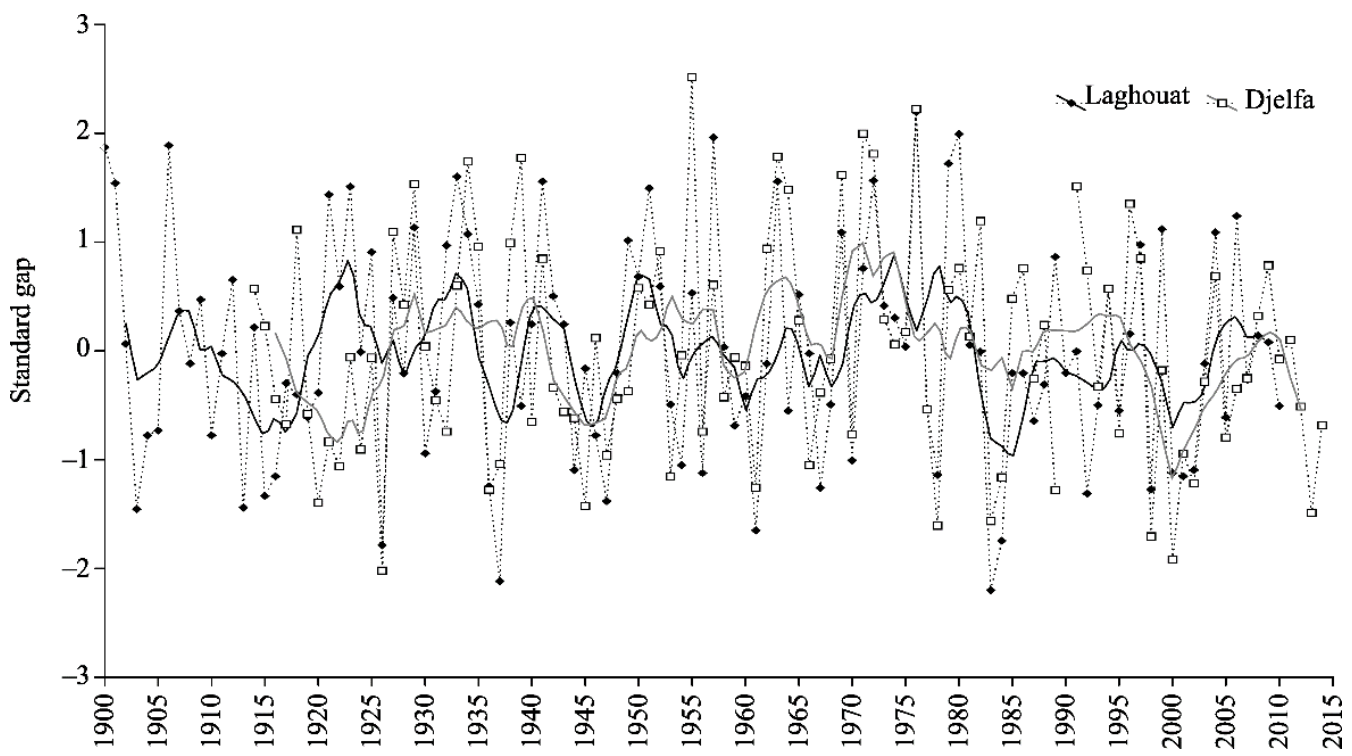

Fig. 3 Evolution of rainfall in the central (Djelfa (semi-arid bioclimate)), and western stations (Laghouat and Ain Sefra (pre-Saharan bioclimate))

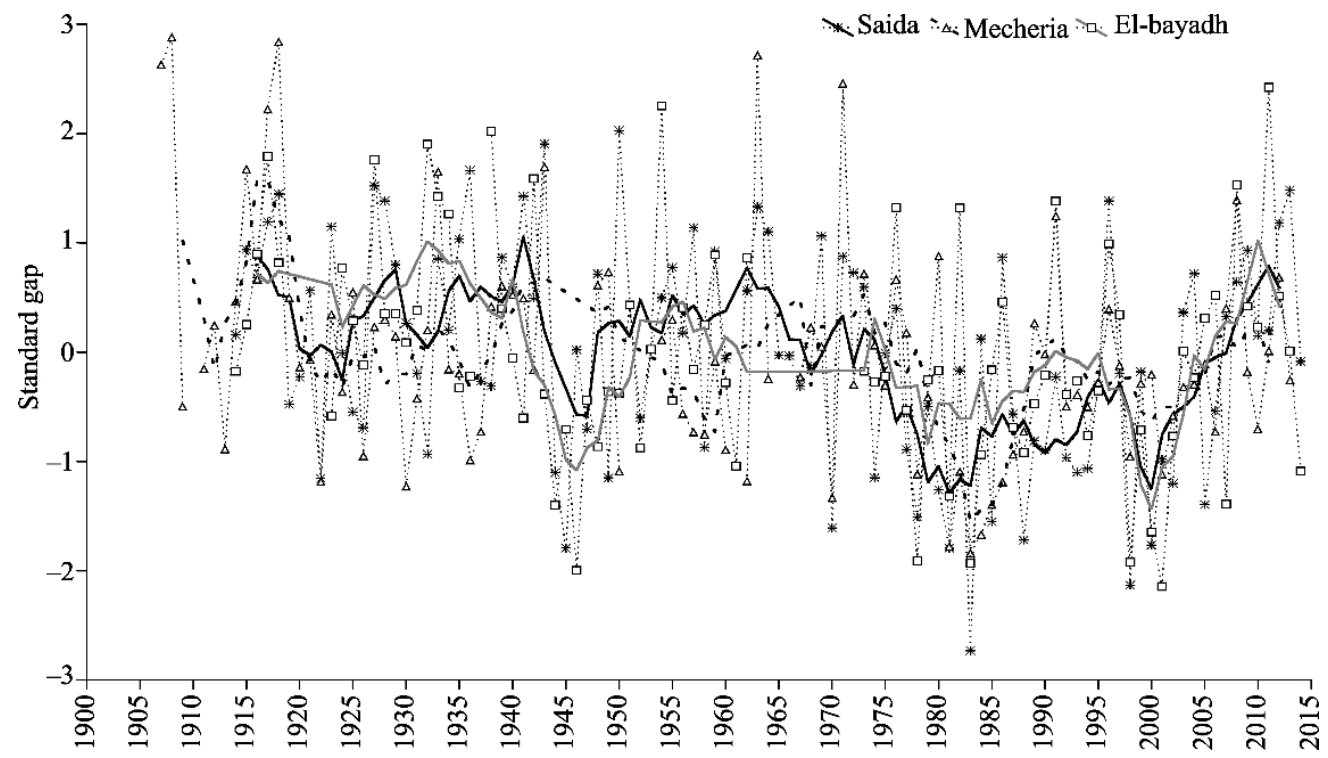

Fig. 4 Evolution of rainfall in the western stations (Saida, Mecheria and El-Bayadh (semi-arid bioclimate))

\subsection{Statistical tests}

\subsubsection{The Mann-Whitney test}

The Mann-Whitney test (Table 4) compares rainfall levels between before and after 1973. The obtained results show significant differences only for the stations of El-Bayadh, Mecheria and Saida in the southwest. The remaining stations present no significant difference between the two periods and consequently show no trend.

3.3.2 The Mann-Kendall test

The results of the Mann-Kendall test (Table 4) confirm the trends shown in Figures 2-4, and the results of the Mann-Whitney test. They are globally in agreement with those obtained by Hirche et al. (2007) with the exception of El-Bayadh. It should be noted that our results for this station are very close to statistical significance thresholds. Only two western stations, Mecheria and Saida, display a decreasing trend. 
Table 4 Results of the Mann-Whitney (M-W) and Man-Kendall (M-K) tests performed on annual rainfall averages of periods 1 and 2 (see Table 1), compared to Hirche et al. (2007) results covering the period 1907-2004.

\begin{tabular}{|c|c|c|c|c|c|c|c|c|c|c|}
\hline & \multirow{2}{*}{ Test } & \multicolumn{4}{|c|}{ Semi-arid bioclimate } & \multicolumn{3}{|c|}{ Pre-Saharan bioclimate } & \multicolumn{2}{|c|}{ Saharan bioclimate } \\
\hline & & EB & $\mathrm{D}$ & $\mathrm{Mh}$ & $\mathrm{Sd}$ & AS & $\mathrm{Bk}$ & Lh & EO & $\mathrm{Tg}$ \\
\hline \multirow[t]{6}{*}{ M-W } & U & 1166.5 & 1251.0 & 1471.0 & 1714.0 & 1340.0 & 1320.5 & 1464.5 & 1224.5 & 1511.0 \\
\hline & Exp & 924.0 & 1218.0 & 1134.0 & 1225.5 & 1376.0 & 1218.0 & 1462.5 & 1075.0 & 1268.5 \\
\hline & $\operatorname{Var}(\mathrm{U})$ & $13,397.87$ & $20,503.00$ & $18,333.00$ & $20,629.12$ & $24,764.00$ & $20,502.51$ & $28,028.00$ & $16,840.91$ & $21,775.92$ \\
\hline & $P$-value & 0.037 & 0.820 & 0.013 & 0.001 & 0.822 & 0.476 & 0.993 & 0.251 & 0.101 \\
\hline & Ho & $\mathrm{R}$ & A & $\mathrm{R}$ & $\mathrm{R}$ & A & A & A & A & A \\
\hline & Result & $*$ & ND & * & $* *$ & ND & ND & ND & ND & ND \\
\hline \multirow[t]{6}{*}{ M-K } & $\mathrm{N}$ & -440.0 & 13.0 & -798.0 & -880.0 & -110.0 & -302.0 & -197.0 & -253.0 & -494.0 \\
\hline & $\operatorname{Var}(\mathrm{N})$ & $57,933.33$ & $109,417.00$ & $99,813.33$ & $109,416.00$ & $126,732.66$ & $112,746.00$ & $153,957.66$ & $64,651.00$ & $69,416.67$ \\
\hline & $P$-value & 0.070 & 0.970 & 0.010 & 0.010 & 0.711 & 0.370 & 0.617 & 0.320 & 0.06 \\
\hline & $\mathrm{H} 0$ & A & A & $\mathrm{R}$ & $\mathrm{R}$ & A & A & A & A & A \\
\hline & Result & ND & ND & $* *$ & $* *$ & ND & ND & ND & ND & ND \\
\hline & Hirche & * & ND & $* *$ & $* *$ & ND & ND & ND & ND & ND \\
\hline
\end{tabular}

Note: *, significant difference; **, very significant difference; ND, no significant difference; EB, El-Bayadh; Dj, Djelfa; Mh, Mecheria; Sd, Saida; AS, Ain Sefra; Bk, Biskra; Lh, Laghoua; EO, El Oued; Tg, Touggour; H0, null hypothesis; Hirche, Hirche et al., 2007; R, rejected; A, accepted; U, Mann-Whitney statistic; Exp, Expected value; Var (U), (U) Variance; N, Mann Kendall statistic; Var (N), (N) Variance.

\subsection{Interactions between climate, vegetation, and human population}

Figure 5 summarizes the evolutions of population, rainfall, livestock and barley production since the beginning of the $20^{\text {th }}$ century in the Mecheria station (NW Algeria), which displays an obvious climate trend toward dryness. Demographic data between 1905 and 1962 is lacking because of unstable social conditions in the region. We note that, despite an overall decrease in rainfall, demographic, livestock and Barley production curves show clearly continuous increasing trends that are accentuated after 1962, with independence.

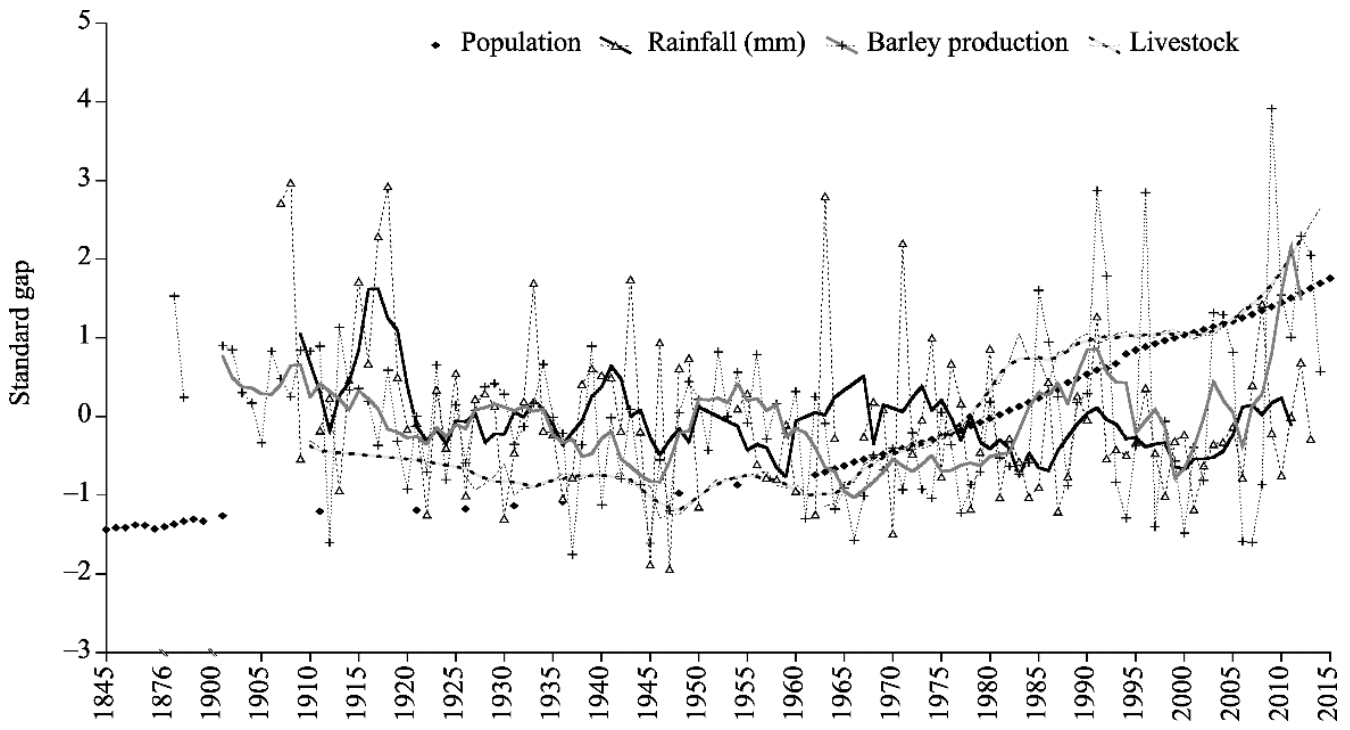

Fig. 5 Evolutions of population, rainfall, barely production and livestock (Mecheria station)

\section{Discussion}

\subsection{Precipitation regime trend in the $20^{\text {th }}$ century}

According to the previous results, the trend toward dryness seems less noticeable in the eastern stations. However, the curves of the western stations show a long drying trend. Indeed, Table 4 shows an obvious trend toward dryness in the southern Oran region, evidenced from 3 climate 
records, and a doubtful trend in the Saharan southern Constantine region, shown only by the ambiguous record of a single station (Touggourt). These regional differences were not sufficiently emphasized in the literature apart from some works, such as Meddi and Meddi (2009a) and Barakat and Handoufe (1998). Those studies suggest that the drought of arid lands increases towards the west. In fact, the central and eastern regions of Algeria do not seem to have been affected by such a significant drought over the long term. In the short term, the recurrence of drought periods is clearly more prominent after the 1970s in all stations, with different durations and intensities. Otherwise, the period 1942-1945 is considered to be the most important drought period during the first part of the century. This particularly dry period (1940-1950) is referred to as one of "misery and famine" coinciding with World War II. The latter half of the century is marked by two dry periods 1981-1989 and 1999-2005. The dry lengths vary depending on the stations.

As long as the studied stations are located in different bioclimates zones, the results among stations are not comparable. From the north to south, the bioclimate varies gradually from humid to the arid. Bioclimatic variability is mostly related to the rainfall latitudinal gradient.

Meddi and Meddi (2004, 2009a, b) found similar results showing drier conditions in the southwest with a greater probability of two consecutive dry years in the west than in the plains of the center. Laborde (1993), on the basis of a synthetic work, found that rainfall shows basically a regressive trend. Kadi (1992) shows that on average, $50 \%-60 \%$ of the meteorological stations are characterized by drought, which illustrates the spatial variability of rainfall between stations.

A study on climate change in Tunisia (GTZ, 2005) did not show any trend over the last century. However, Kingumbi et al. (2001) found a pluviometry deficit of $10 \%$ to $35 \%$ and even $50 \%$ for the period 1999-2002, which should nuance the previous results. By contrast, Morocco seems particularly affected by the drought (Gravier and Weisrock, 1986; Meddi and Meddi, 2004). There is an expansion of dry farming over the past twenty years, which suggests the hypothesis of an aridification gradient towards the west. Even if the limited number of stations makes it difficult to claim the existence of a dryness gradient from the east to west, earlier results are coherent with this hypothesis. This gradient could be linked to the activity of the anticyclone of the Azores and of the North Atlantic oscillation.

\subsection{Spatial distribution of rainfall changes}

Different variation rates in rainfall can be distinguished. The lowest $(<10 \%)$ are mainly observed in the southern region of Algiers: Djelfa (4.7\%) and Laghouat (4.3\%). Rates between 10\% and 20\% are observed in the southern Constantine region (Biskra, 13.9\%; El Oued, 11.9\%) and in the southern Oran region (El-Bayadh, 15.7\%). All these stations are located in the pre-Saharan bioclimate, with the exception of El-Bayadh, located in a mountainous zone. The western steppe stations present rates exceeding 20\% (Mecheria, 26.8\%; Saida, 22.3\%). Ghenim et al. (2014) found $29 \%$ in the same region, and Meddi et al. (2010) found 20\% in the Mitidja (Algiers region). Rates vary from $10 \%$ to $55 \%$ in Tunisia (Kingumbi et al., 2001; Gargouri et al., 2008) and from $8 \%$ to $30 \%$ in Morocco (Sebbar et al., 2011) while Philippe (2007) found a variation between $10 \%$ to $20 \%$ in North Africa. These discrepancies can be explained by the heterogeneity in the choice of stations, reference periods and statistical tests.

Some studies show a drying trend prior to the end of the 1980s (Daget and Djellouli, 1991) in Algeria, but reveal a break of stationarity of statistical series in 1970 (Meddi and Hubert, 2003). Other studies show that the western region was more affected by drought (Medjerab and Henia, 2005; Meddi and Meddi, 2009b), Benabadji and Bouazza (2000) first noted the dry period was growing longer on ombrothermic diagrams. The same decreasing trend of rainfall has been identified in eastern Morocco adjacent to the southern Oran region (Mahyou et al., 2010; Mahyou, 2012; Bechchari et al., 2015).

\subsection{Impact of climate change and human activities on steppe rangelands}

The field vegetation survey confirms the huge draught, especially during the 1980s. Alfa (Stipa tenacissima) and sagebrush (Artemisia herba-alba) rangelands have disappeared in southwestern Algeria and became rare in the other regions. At the same time, other species such as Atractylis 
serratuloides and Salsola vermiculata have expanded in the study area (ROSELT, 2005). In such degraded areas, current plant cover rarely exceeds 15\% (Hirche, 2010; Hourizi et al., 2017).

While both rainfall and phytomass display decreasing trends at the century scale, Figure 6 suggests that these two trends are not linked. Such a disconnection, which is not observed in the Sahel region (Gagnol and Soubeyran, 2012) reveals the influence of human activities. In fact, population in the region have increased since 1962 along with expanding livestock and barley production (Fig. 5). The phytomass of the Algerian steppes then seems to be triggered first by human activities and second by climate forcing.

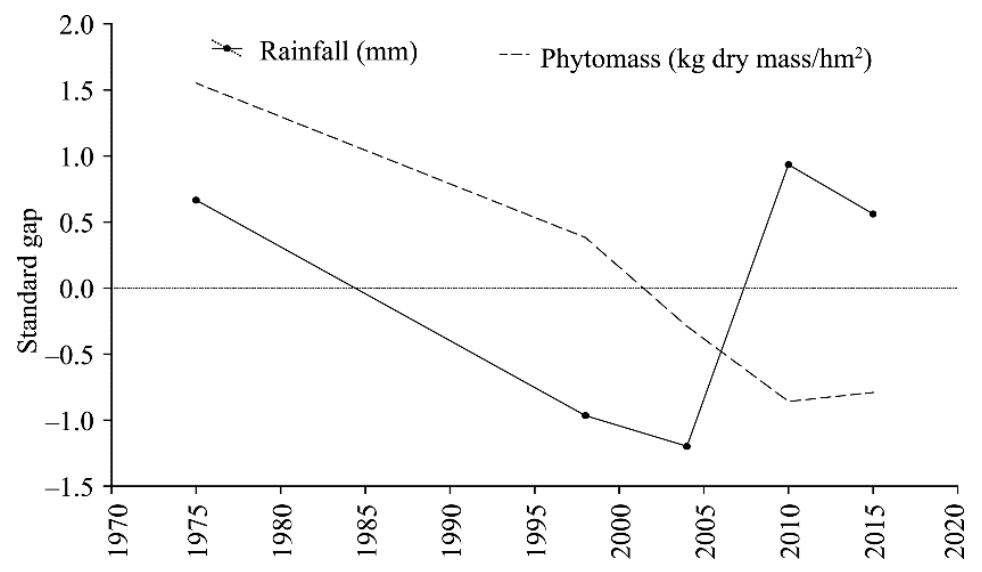

Fig. 6 Evolution of rainfall and phytomass (Mecheria station)

Rainfall increased in 2004-2015, which had a relatively positive impact on the Algerian steppe landscape (Hourizi et al., 2017). Biodiversity, biomass and vegetation cover increased slightly but not sufficiently to reverse the desertification process.

The importance of the end-of-series in the general shape of the trend curve is well known (Leurion, 1975). This could explain, in part, the absence of drought trends at the century scale. The results show that recent wet years have reduced the sharpness of the drying trend in South Oran. If the coming years are still wet, it is likely that the drying trend disappears even in southern Oran. This highlights the relativity of the notion of trend and the importance of the investigated period. Ultimately, although there does not appear to be a statistically significant change in rainfall, the detailed study of its distribution shows that rainfall is irregular during the century and the frequency of droughts has increased in the last decades.

The rangelands of the southern Oran region have a major economic importance since they are home to the main part of the national livestock. During the last thirty years, the difference between supply and demand for fodder resources has increased, leading to overgrazing which has directly impacted rangelands that have progressively declined. The southern Oran rangelands are continuous with the eastern Moroccan steppes, which have experienced the same trend of decreasing rainfall (Mahyou et al., 2010; Mahyou, 2012).

\section{Conclusions}

This work provides the first reconstruction of the 100-year evolution of rainfall (1900-2014) at the scale of the Algerian steppes, including the high plains, pre-Saharan, and Saharan regions. Despite limited available reliable meteorological data, which constrains the scope of our conclusions, the results are fairly convergent and seem consistent and show a decadal variability of rainfall in the entire steppe region, and a tendency to aridification only in the southwestern steppe region, with three particularly dry periods in 1940-1950, 1980-1985 and 1999-2004. Moreover, the period 1900-1972 is generally more humid with wet periods alternating with dry periods more regularly, and the period 1973-2014 is drier. The regional vegetation degradation (expansion of grazingtolerant plant formations replacing the initial steppes of alfa, esparto and sagebrush) consequently 
appears not to have been triggered by climate change but rather by the strong contemporary increase in human activities, livestock and barley production.

\section{Acknowledgements}

This research was funded by the Ministère de l'Enseignement Supérieur et de la Recherche Scientifique of Algeria. The paper is the contribution ISEM 2017-250. We are deeply grateful to Mr Djamel BOUCHERF and Dr. Charlie FAVIER for providing missing climate data, to Dr. Doroth GLASSMAN for editorial assistance and to anonymous reviewers for helpful comments.

\section{References}

Aidoud A, Aidoud L F, Slimani H. 1998. Effects of grazing on soil and desertification: a review from the southern Mediterranean rim. In: Papanastasis VP, Peter D. Ecological basis of livestock grazing in Mediterranean ecosystems. Thessaloniki: Office for Official Publications of the European Community, 23-25.

Barakat F, Handoufe A. 1998. Agro-climatic approach to agricultural drought in Morocco. Science and Planetary Changes/Drought, 9(3): 201-208. (In French)

Bechchari A, El Aich A, Mahyou H, et al. 2015. Analysis of pastoral ecosystem in Eastern the Morocco. Journal of Livestock and Veterinary Medicine of the Tropics, 67(4): 151-162. (In French)

Benabadji N, Bouazza M. 2000. Some climate changes occurred in Southwest of Oran (Western Algeria). Renewable Energy Review, 3(2): 117-125. (In French)

Benbrahim K F, Ismaili M, Benbrahim S F, et al. 2004. Problems of environmental degradation through desertification and deforestation: impact of the phenomenon in Morocco. Science and Planetary Changes/Drought, 15(4): 307-320. (In French)

Design Office of Rural Development of Algeria (BNEDER). 2006. Identification and mapping of the agriculture areas in steppe zones: diachronic study of the climate and bioclimate of the Algerian steppe, 47. (In French)

Daget P, Djellouli Y. 1991. Is the Mediterranean climate changing? The drought in Algiers over the last hundred years. Publication of the International Association of Climatology, 4: 187-195. (In French)

Djebaili S. 1978. Phytosociological and phytoecological research on the vegetation of the High Steppes Plains and the Algerian Saharan Atlas. PhD Dissertation. Montpellier: University of Montpellier. (In French)

Djellouli Y. 1981. Climate and bioclimatic study of the southern high plains of Oran: Saida Wilaya. Behavior of species depending on the climate elements. PhD Dissertation. Algiers: Houari Boumediene University of Sciences and Technology. (In French)

Djellouli Y. 1990. Flores and climates in northern Algeria. Climatic determinisms of plant distribution in Algiers. PhD Dissertation. Algiers: University of Sciences and Technology Houari Boumediene. (In French)

Djellouli Y, Daget P. 1993. Consequence of the drought of the last two decades on the Algerian natural ecosystems. Publication of the International Association of Climatology, 6: 104-113. (In French)

Gagnol L, Soubeyran O. 2012. Adapt to adaptation. The Sahelian condition is challenged by the injunction to climate change. Geography and Cultures, 81: 1-12, doi: 10.4000/gc.200. (In French)

Gargouri K, Rhouma A, Sahnoun A, et al. 2008. Assessment of the climate change impact on growing up in Tunisia using GIS tools. Mediterranean Options Series A 80: 349-352. (In French)

Ghenim A, Megnounif A, Djelloul S. 2014. Assessment of changes in the rainfall of the Tafna watershed (northwestern Algeria). In: Laignel B, Nouaceur Z. Water and Climate. El Hammamat: Water and Climate Network, 2: 66-77. (In French)

Gonzalez P, Tucker C J, Sy H. 2012. Tree density and species decline in the African Sahel attributable to climate. Journal of Arid Environments, 78: 55-64.

Gravier J, Weisrock A. 1986. An example of a climatic accident, the drought of 1975-1984 in Morocco. In: Climate and Natural Risk. Paris: French Association of Physical Geography, 139-148. (In French)

Gesellshaft für technische Zusammenarbeit (GTZ). 2005. Climate change: effects on the Tunisian economy and adaptation strategy for the agricultural sector and natural resources. Summary Report, the $1^{\text {st }}$ Step. Tunis: Ministry of Agriculture and Hydraulic Resources. (In French)

Hamed K, Rao A R. 1999. Flood Frequency Analysis. Boca Raton, Florida: CRC Press.

Hanafi A, Jauffret S. 2008. Are long-term vegetation dynamics useful in monitoring and assessing desertification processes in the arid steppe, southern Tunisia? Journal of Arid Environments, 72: 557-572.

Herrmann S M, Anyamba A, Tucker C J. 2005a. Exploring relationship between rainfall and vegetation dynamics in the Sahel 
using coarse resolution satellite data. In: Global Monitoring for Sustainability and Security. St Petersburg: International Symposium on Remote Sensing of Environment, 79.

Herrmann S M, Anyamba A, Tucker C J. 2005b. Recent trends in vegetation dynamics in the African Sahel and their relationship to climate. Global Environmental Change, 15: 394-404.

Herrmann S M, Hutchinson C F. 2005. The changing contexts of the desertification debate. Journal of Arid Environments, 63: 538-555.

Hirche A. 2010. Assessment of the contribution of the spatial remote sensing in the dynamics of ecosystems in arid zones: SouthOran case. PhD Dissertation. Algiers: Houari Boumediene University of Sciences and Technology. (In French)

Hirche A, Boughani A, Salamani M. 2007. Annual rainfall evolution of in some Algerian dry stations. Science and Planetary Changes/Drought, 18: 314-320. (In French)

Hirche A, Salamani M, Abdellaoui A, et al. 2011. Landscape changes of desertification in arid areas: the case of south-west Algeria. Environmental Monitoring and Assessment, 179: 403-420.

Hourizi R, Hirche A, Djellouli Y, et al. 2017. Spatio-temporal changes in the steppe landscapes of Algeria. Case of Mechéria region. Ecology Journal (Earth and Life), 72 (1): 33-47. (In French)

Kadi M. 1992. Some aspects of drought in North Africa and in the Mediterranean basin. In: Tropical Climates and Their Evolution. Toulouse: National Center for Space Studies. (In French)

Kingumbi A, Bergaoui Z, Bourges J, et al. 2001. The evolution of the rainfall series study of Central Tunisia. In: Servat E, Albergel J. Hydrology of the Mediterranean Regions. Montpellier: Inland Revenue Department, 341-345. (In French)

Laborde J. 1993. Rainfall map of northern Algeria at the scale of 1/500 000, explanatory note. Project UNDP/ALG/88/02. Algiers: National Agency for Hydraulic Resources. (In French)

Le Houérou H. 1989. The variability of annual rainfall in some arid regions of the world; its ecological consequences. In: Bret B (dir.). Men facing drought (Northeast Brazil and African Sahel). Works and memories collection. Paris: IHEAL, 127-137. (In French)

Le Houérou H N. 1996. Climate change, drought and desertification. Journal of Arid Environments, 34(2): $133-185$.

Lhote H. 1975. The rock engravings of Oued Djerat: (Tassili-n-Ajjer). Memory of the CRAPE n 2. Algiers: Center of Prehistoric and Ethnographic Researches, 426-830. (In French)

Mahyou H. 2012. Application of geomatics for the assessment of pastoral resources in Morocco. PhD Dissertation. Arlon: University of Liege.

Mahyou H, Tychon B, Balaghi R, et al. 2010. Desertification of arid rangelands in Morocco. Tropicultura, 28: 107-114. (In French)

Ministry of Agriculture and Agrarian Reform of Algeria (MARA). 1974. "The Algerian steppe": Agricultural Statistics, 14. (In French)

Meddi H, Meddi M. 2004. Drought and spatialization of precipitation in northwestern Algeria. In: Djabri L. Proceedings of the "Earth and Water Symposium". Annaba: Badji Mokhtar University, 31-34. (In French)

Meddi H, Meddi M. 2009a. Study of the persistence of drought in seven Algerian plains using Markov chains (1930-2003). Mail of Knowledge, 9: 39-48. (In French)

Meddi H, Meddi M. 2009b. Variability of annual rainfall in northwestern Algeria. Science and Planetary Changes/Drought, 20: 57-65. (In French)

Meddi M, Hubert P. 2003. Impact of the modification of the rainfall regime on the water resources of North-West Algeria. In: Servat E, Najem W, Leduc C, Shakeel A. Hydrology of the Mediterranean and semi-arid regions. Montpellier: IAHS Publication, 229-235. (In French)

Meddi M M, Assani A A, Meddi H. 2010. Temporal variability of annual rainfall in the Macta and Tafna catchments, Northwestern Algeria. Water Resources Management, 24: 3817-3833.

Medjerab A, Henia L. 2005. Rainfall survey of North-West Algeria (statistical approach and automatic mapping). PhD Dissertation. Algiers: University of Sciences and Technology Houari Boumediene. (In French)

Muzzolini A. 1993. Reasoned chronology of the various rock art schools of the central Sahara. Memories of the Italian Society of Natural Science and of the Civic Museum of Natural History in Milan, 26: 387-397. (In Italian)

Nedjraoui D. 2003. Mechanisms to monitor desertification in Algeria, proposal of a national long-term ecological monitoring. ROSELT/OSS documents. Biskra, Algeria: Network of Long-Term Ecological Monitoring Observatories, 37. (In French)

Nicholson S. 2000. Land surface processes and Sahel climate. Reviews of Geophysics, 38: 117-139.

Nicholson S. 2005. On the question of the "recovery" of the rains in the West African Sahel. Journal of Arid Environments, 63: 
$615-641$.

Philippe J. 2007. Agricultural practices, natural resource management and climate change in the Maghreb and sub-Saharan Africa. In: International solidarity for a strategy on climate change in the African and Mediterranean regions. Tunis: Ministry of the Environment and Sustainable Development. (In French)

Quézel P, Santa S.1962. New Flora of Algeria and Southern Desert Regions (2 volumes). Paris: CNRS. (In French)

Reynolds J F, Smith D M S, Lambin E F, et al. 2007. Global desertification: building a science for dry land development. Science, 316: 847-851.

ROSELT. 2005. Final report of the observatory of the high steppe plains of southern Oran. OSS/ROSELT/CRSTRA project. Biskra: Network of Long Term Ecological Monitoring Observatories. (In French)

Sebbar A, Badri W, Fougrach H, et al. 2011. Study of the rainfall regime variability in northern Morocco (1935-2004). Science and Planetary Changes/Drough, 22: 139-148. (In French)

Seltzer P, Lasserre A, Grandjean A, et al. 1946. The Algerian Climate. Algiers: Carbonel. (In French)

Slimani H, Aidoud A, Roze F. 2010. 30 Years of protection and monitoring of a steppic rangeland undergoing desertification. Journal of Arid Environments, 74: 685-691.

Sneyers R, Tuomenvirta H, Heino R. 1998. Observations inhomogeneities and detection of climate change: The case of the Oulu (Finland) air temperature series. Geophysica, 34: 159-178.

Sprent P. 1992. Practice of Non-Parametric Statistics. Paris: INRA. (In French)

Wilcoxon F. 1945. Individual comparisons by ranking methods. Biometrics Bulletin, 1: 80-83. 